\title{
THEORETICAL INVESTIGATION OF ENVIRONMENTAL DEVELOPMENT PATHWAYS IN THE ROAD TRANSPORT SECTOR IN THE EUROPEAN REGION
}

\author{
Gabor Szendrő ${ }^{1}$, Ádám Török ${ }^{2}$ \\ ${ }^{1}$ Dept of Environmental Economics, Budapest University of Technology and Economics, Hungary \\ ${ }^{2}$ Dept of Transport Economics, Budapest University of Technology and Economics, Hungary
}

Submitted 30 May 2012; accepted 24 October 2012

\begin{abstract}
With the omnipresent influence of mankind around the world, controlling resource use and pollution are key factors in the progress toward sustainability in all sectors. These considerations appear in international and European policies, but there remains a need to make these policies suited to local conditions. This article aims to present a method of analysis for the transport sector that could prove useful for identifying the similarities and differences in the current state and historical development of transport systems in EU Member States.
\end{abstract}

Keywords: environmental pollution, road transport, statistical assessment.

Reference to this paper should be made as follows: Szendrő, G.; Török, Á. 2014. Theoretical investigation of environmental development pathways in the road transport sector in the European Region, Transport 29(1): 12-17.

http://dx.doi.org/10.3846/16484142.2014.893538

\section{Introduction}

Human activity, despite being present for but the brief, most recent period in our planet's history, is now shaping Earth more than any other geological factor, as human dominance affects almost all biological systems (Fig. 1).

This fundamental reality has even given rise to new terms in measuring geologic time, calling where we cur-

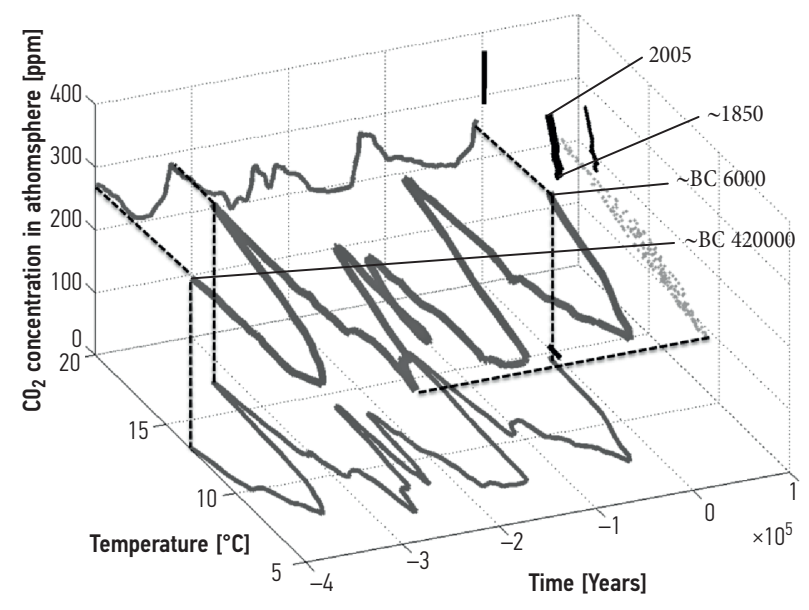

Fig. 1. Average atmospheric $\mathrm{CO}_{2}$ and average Earth temperature complex time series (Török 2009) rently are the 'Anthropocene' (Liao et al. 2012). This is the dominance of man - an epoch that started with the industrial revolution which has led to an exponential growth of human impact around the planet, and bringing about an unprecedented increase in human populations (from 1 billion to 7 billion) (Lee 2011). A large part of this boom was literally fuelled by oil, as the use of fossil fuels has enabled new methods for producing, transporting and consuming goods, but also releasing enormous amounts of pollution and greenhouse gases into the atmosphere (Fig. 2).

Authors are aware of the historical changes in the area of EU. In order to understand the changes over time, authors have investigated all EU-27 countries through time series data from 1991, irrespective of their Member State status. The data analysed in such a way not only shows differences between Member States and countries outside the EU, but also shows the effects of implementing EU policies.

With the extended lifespan that modern health care provides (that also increases the time spent with less than full health, increasing the need for transport services) (Shroufi et al. 2011) and unrelenting global economic growth, our resource use is sharply rising a clear indication that the Anthropocene requires new approaches and tools in all areas. The transport sector is

Corresponding author: Gabor Szendrö

E-mail: szendro@eik.bme.hu 


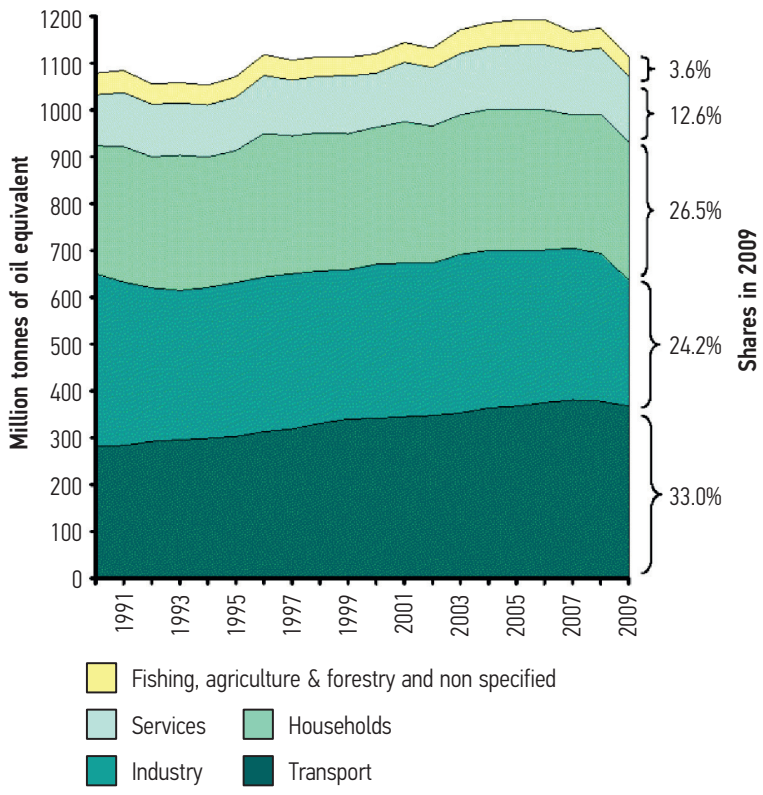

Fig. 2. Total energy consumption by sector in the EU-27 region, 1991-2009 (EEA 2009, 2011)

no exception, as a considerable share of costs occurs as externalities - integrated strategies and coordinated actions are necessary to minimize these costs (Csete, Horváth 2012). Responsibility for a portion of both parts of the equation (pollution and externalities vs. economic growth and standard of living), is one of the focus areas for policy intervention in the European Union and around the globe. The challenge is great: any successful policy must be stringent enough to achieve results, but it must also be sufficiently realistic in terms of what it can achieve so as not to hinder economic growth, especially in the current crisis. But, perhaps the greatest challenge of them all is to somehow reconcile the fundamental differences between countries and their respective transport systems while maintaining a uniform set of objectives and tools. This article aims to provide a basic tool to monitor the development of passenger transport in different countries using readily available statistical data so that future strategies can be formulated in a way that takes regional differences into account.

\section{Methodology}

In order to form convergent groups, investigated countries have been clustered based on their average transport-related $\mathrm{CO}_{2}$ emissions, rate of motorization and the development of emissions per passenger car unit. In order to determine which clusters should be combined, (in this case, authors have used agglomerative cluster analysis) a measurement of dissimilarity between sets of observations is required. Authors have defined a dissimilarity matrix with the Euclidean metric (a measure of distance between pairs of observations) that specifies the dissimilarity of investigated countries (Chari et al. 2012).

Further, on the emissions of the transport systems of analysed countries have been investigated to deter- mine development trends in each cluster. Investigated datasets were motorization rate (in this instance expressed as PCU/person) and specific annual emissions per Passenger Car Unit (PCU). Plotting these indicators on an $X Y$ diagram, the development trends become clear and clusters can be compared. Being aware of these trends on a European level is important because strategies can be adapted to reflect the situation in each country. For data input, authors have used the dataset provided by the European Environmental Agency (EEA 2009,2011 ) for $\mathrm{CO}_{2}$ emissions (ton $\mathrm{CO}_{2}$ per capita) and the rate of motorization (passenger car unit per capita) by Eurostat (http://epp.eurostat.ec.europa.eu). Due to constraints in available space, the aggregated database is not included in the text, having 81 rows and 20 columns. Authors have calculated and investigated the development of the emission factor of passenger car units in different countries:

$$
\theta(t)=\frac{\varepsilon(t)}{m(t)},
$$

where: $\theta$ - emission factor of passenger car unit $\left[\mathrm{tCO}_{2} /\right.$ PCU]; $\varepsilon$ - country specific emission factor $\left[\mathrm{tCO}_{2} /\right.$ person]; $m$ - rate of motorization [PCU/1000 inhabitants]; $t-$ year of analysis.

Authors have used the aggregated data of Eurostat (http://epp.eurostat.ec.europa.eu). According to their definition: 'Vehicle stock of passenger cars, light and heavy duty trucks, buses/coaches and two-wheelers are summarized as follows: one car is considered as a single unit, cycles, motorcycles are considered as half a car unit. Buses, trucks cause a lot of inconvenience because of their large size and are considered equivalent to 3 cars or 3 PCU'. These aggregated numbers were divided by population. $83 \%$ of transport energy is consumed by road transport. This mode remains by far the largest single emitter. According to the European Environment Agency (EEA 2009, 2011), 93 \% of greenhouse gas emissions from transport came from road transport in 2004. Let us assume that dataset can be described as a set of $3 \mathrm{D}$ vectors:

$$
v_{i}(e m i, m o t, t)
$$

where: $v_{i}$ - vector of emission, motorization and time; emi - emission factor of PCU $\left[\mathrm{tCO}_{2} / \mathrm{PCU}\right] ;$ mot - rate of motorization [PCU/person]; $t$ - year of analysis

According to the database, the impact of transit vehicle flows could not be calculated as the number of registered vehicles and emissions are country-specific. For further analysis, $v_{i}$ vectors should be converted from the Cartesian coordinate system to a polar coordinate system, as shown:

$$
\begin{aligned}
& \left(v _ { i } \left(=\sqrt{\left(e m i^{2}+m o t^{2}\right)} ;\right.\right. \\
& \alpha=\operatorname{arctg}\left(\frac{m o t}{e m i}\right) .
\end{aligned}
$$

From that the $v_{i}$ vector, the polar coordinates will be as follows: 


$$
v_{i}\left(\left|v_{i}\right|, \alpha, t\right)
$$

where: $\left|v_{i}\right|$ - Euclidian length of vector $i[-] ; \alpha-$ angle between vector $i$ and the horizontal axis $\left[^{\circ}\right]$.

Authors have cross-checked the cluster analysis of the dataset on the basis of polar coordinates and found no significant differences.

\section{Results}

From the dissimilarity matrix, with the help of SPSS (Statistical Package for the Social Sciences), a dendogram has been built (Fig. 3). It is worth noting that Luxembourg has been disaggregated from any group for the sake of consistency as its indicators are far above that of any other country. With the omission of Luxembourg, 4 different clusters, or groups of countries have been identified, creating a base of analysis for further investigation (Fig. 3).

As it can be seen, four different groups have been created. The first group (Group I) contains countries that used to have very low rate of motorization and considerable transport related $\mathrm{CO}_{2}$ emissions (e.g. Hungary, Slovakia). These countries have seen significant evolution in recent years (Fig. 4) in both dimensions.

The overall impact of the transport system is these countries could be decreased through the use of taxes (such as the introduction of the registration tax in Hungary), while external impacts, such as the economic crisis, have also had significant effect (IRU 2009).

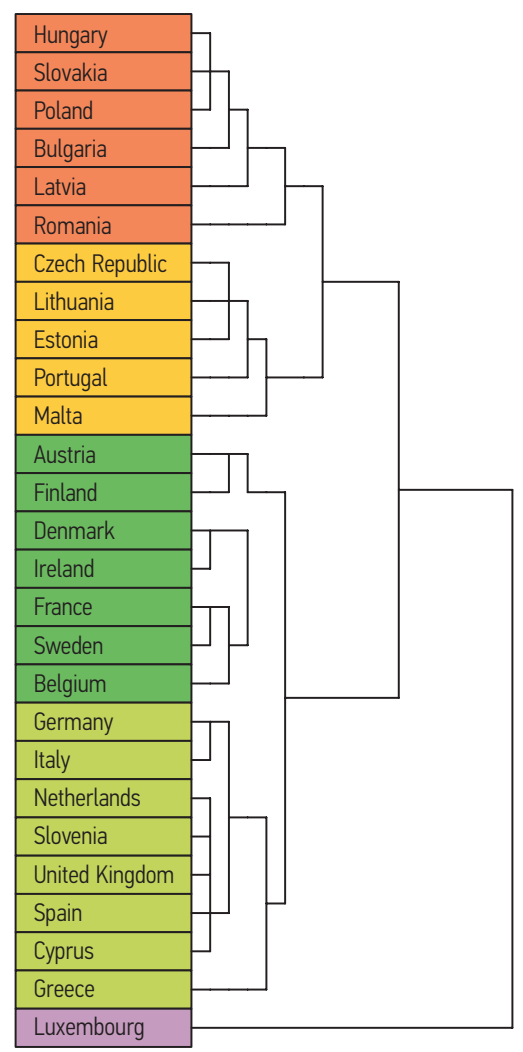

Fig. 3. Dendogram of the cluster analysis (source: own compilation)
The second group (Group II) contains countries where specific emissions are decreasing, but the motorization rate is sharply increasing (our analysis has shown Lithuania to be such a country); the renewal of the vehicle fleet will prove more effective to mitigate the overall impacts of the transport system (ITF 2011) (Fig. 5).

For countries in the third group (Group III), motorization rate has already stabilized and huge effort has been made to pursue environmental protection (such as Sweden, Finland or Austria), necessitating a different set of measures for this group (Fig. 6).

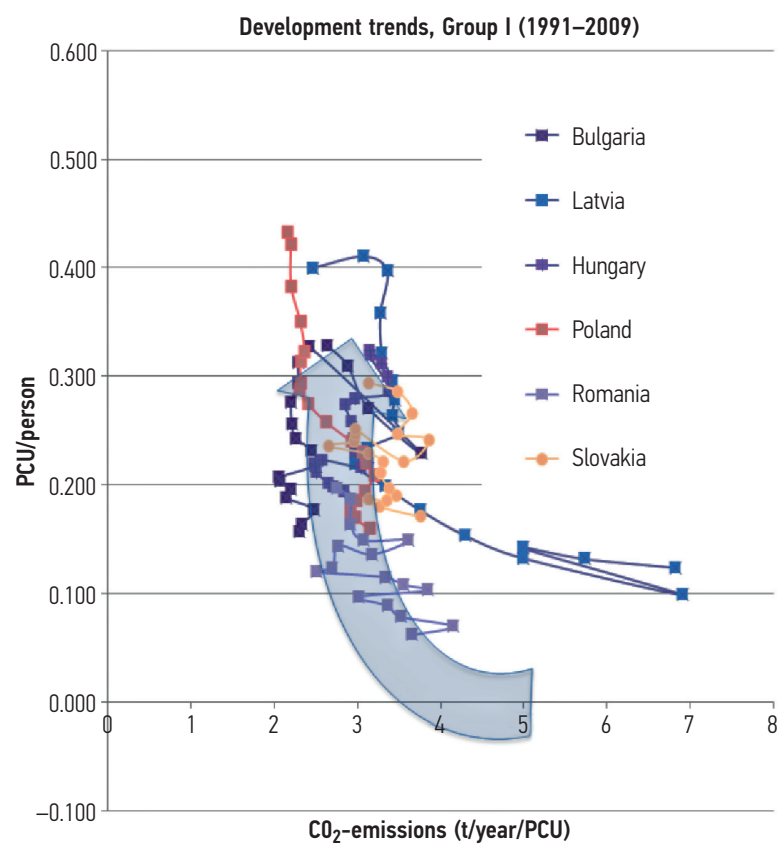

Fig. 4. Development tendencies in Group I (source: own compilation)

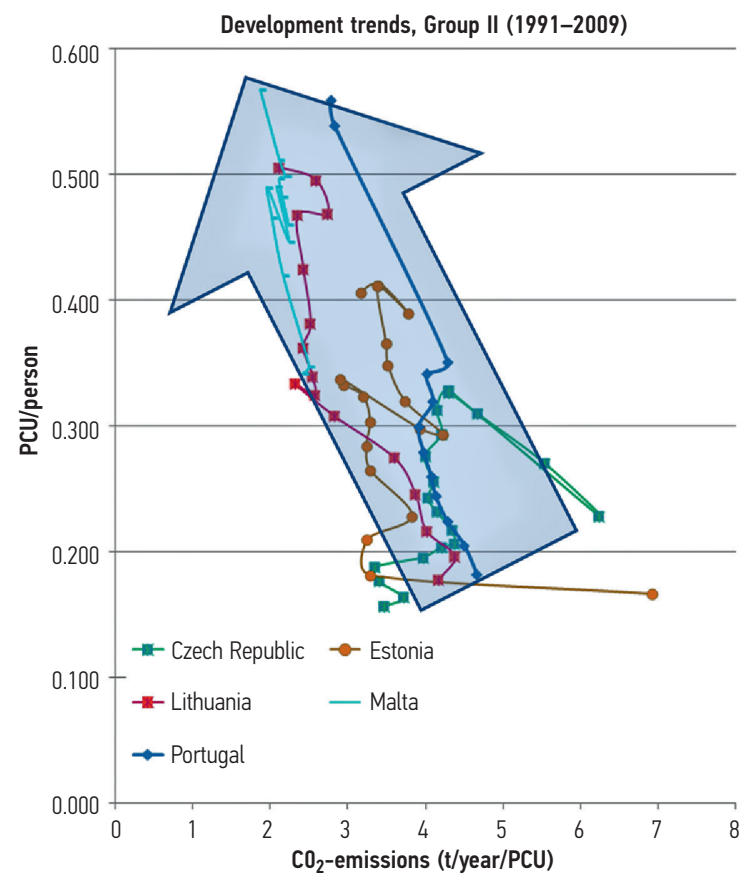

Fig. 5. Development tendencies in Group II (source: own compilation) 


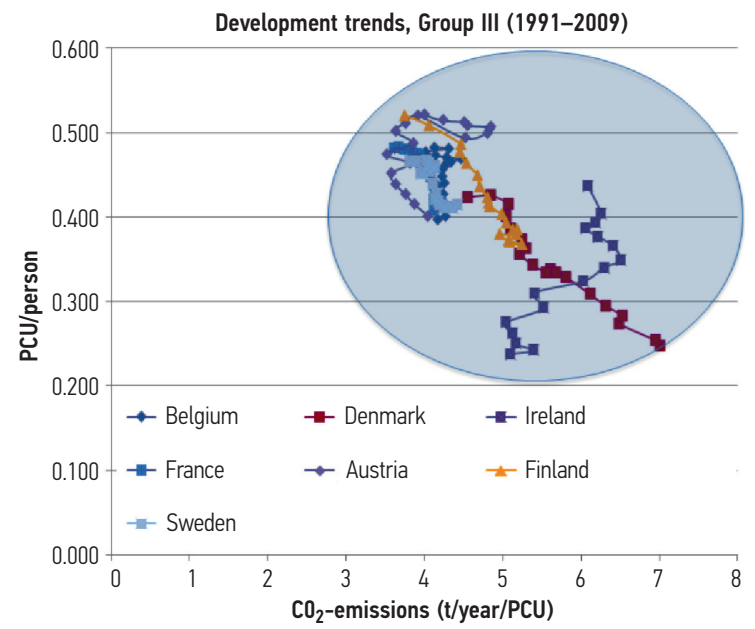

Fig. 6. Stabilized motorization in Group III (source: own compilation)

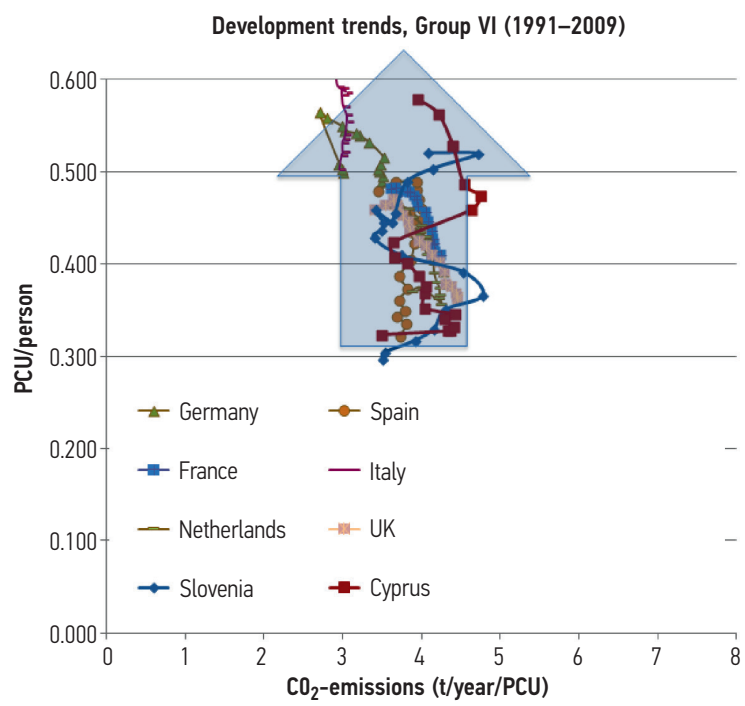

Fig. 7. Significant evolution in motorization in Group IV (source: own compilation)

The fourth group (Group IV) shows significant development in the transport sector with a less significant evolution in environmental protection for the last two decades (Fig. 7).

\section{Analysis}

To take the analysis further, it is useful to convert to polar coordinates introducing the angle with the horizontal axis and Euclidean vector length (Eq. 5). The evolution of countries has been analysed based on the difference in angle and vector length as a function of time (Table).

In the Table, the country with the greatest change in the assessment period has been considered as $100 \%$, and all other countries have been expressed as a percentage of that value.

Please note that the average deviance in vector length compared to the longest vector is $14.4 \%$. The average deviance in the angle between the different vectors and the horizontal axis compared to the biggest angle is $33.8 \%$.

Table. Comparison of deviance in polar coordinates (source: own compilation)

\begin{tabular}{lcc}
\hline Belgium & $2.5 \%$ & $10.9 \%$ \\
\hline Bulgaria & $9.5 \%$ & $33.5 \%$ \\
\hline Czech Republic & $16.1 \%$ & $17.7 \%$ \\
\hline Denmark & $13.7 \%$ & $25.8 \%$ \\
\hline Germany & $8.5 \%$ & $51.1 \%$ \\
\hline Estonia & $22.3 \%$ & $46.3 \%$ \\
\hline Ireland & $8.1 \%$ & $12.0 \%$ \\
\hline Greece & $39.0 \%$ & $34.5 \%$ \\
\hline Spain & $3.2 \%$ & $23.4 \%$ \\
\hline France & $3.4 \%$ & $16.1 \%$ \\
\hline Italy & $2.3 \%$ & $26.2 \%$ \\
\hline Cyprus & $7.1 \%$ & $31.6 \%$ \\
\hline Latvia & $24.6 \%$ & $65.6 \%$ \\
\hline Lithuania & $53.6 \%$ & $100.0 \%$ \\
\hline Luxembourg & $100.0 \%$ & $22.1 \%$ \\
\hline Hungary & $5.1 \%$ & $15.4 \%$ \\
\hline Malta & $3.2 \%$ & $70.5 \%$ \\
\hline Netherlands & $3.2 \%$ & $18.6 \%$ \\
\hline Austria & $7.4 \%$ & $17.1 \%$ \\
\hline Poland & $5.6 \%$ & $65.7 \%$ \\
\hline Portugal & $10.3 \%$ & $71.4 \%$ \\
\hline Romania & $9.2 \%$ & $24.4 \%$ \\
\hline Slovenia & $7.6 \%$ & $25.5 \%$ \\
\hline Slovakia & $6.7 \%$ & $30.3 \%$ \\
\hline Finland & $8.2 \%$ & $12.4 \%$ \\
\hline Sweden & $3.4 \%$ & $2.7 \%$ \\
\hline United Kingdom & $5.8 \%$ & \\
\hline
\end{tabular}

\section{Conclusions}

The method introduced above is useful for tailoring transport policy to groups of countries in the EU to maximize policy effectiveness. Authors have adapted the BCG matrix to the transport sector based on the dataset. The BCG model is a well-known portfolio management tool. Authors have designed an environmental BCG matrix to distinguish between clusters (Fig. 8). First, authors have investigated the historical penetration of road vehicles. This is described by the blue arrows. Second, the clusters were placed in the matrix.

Based on our cluster analysis, the transport management tools suited for the different groups are the following:

- Dogs (Group I) - following European vehicle standards, the potential for these countries lies in curbing the continued increase in motorization. Measures such as registration tax, congestion charge, parking regulations, and other fiscal measures could be used effectively (Beck et al. 2011; Szendrö 2011). The evolution possibilities for the cluster are described by green arrows. 


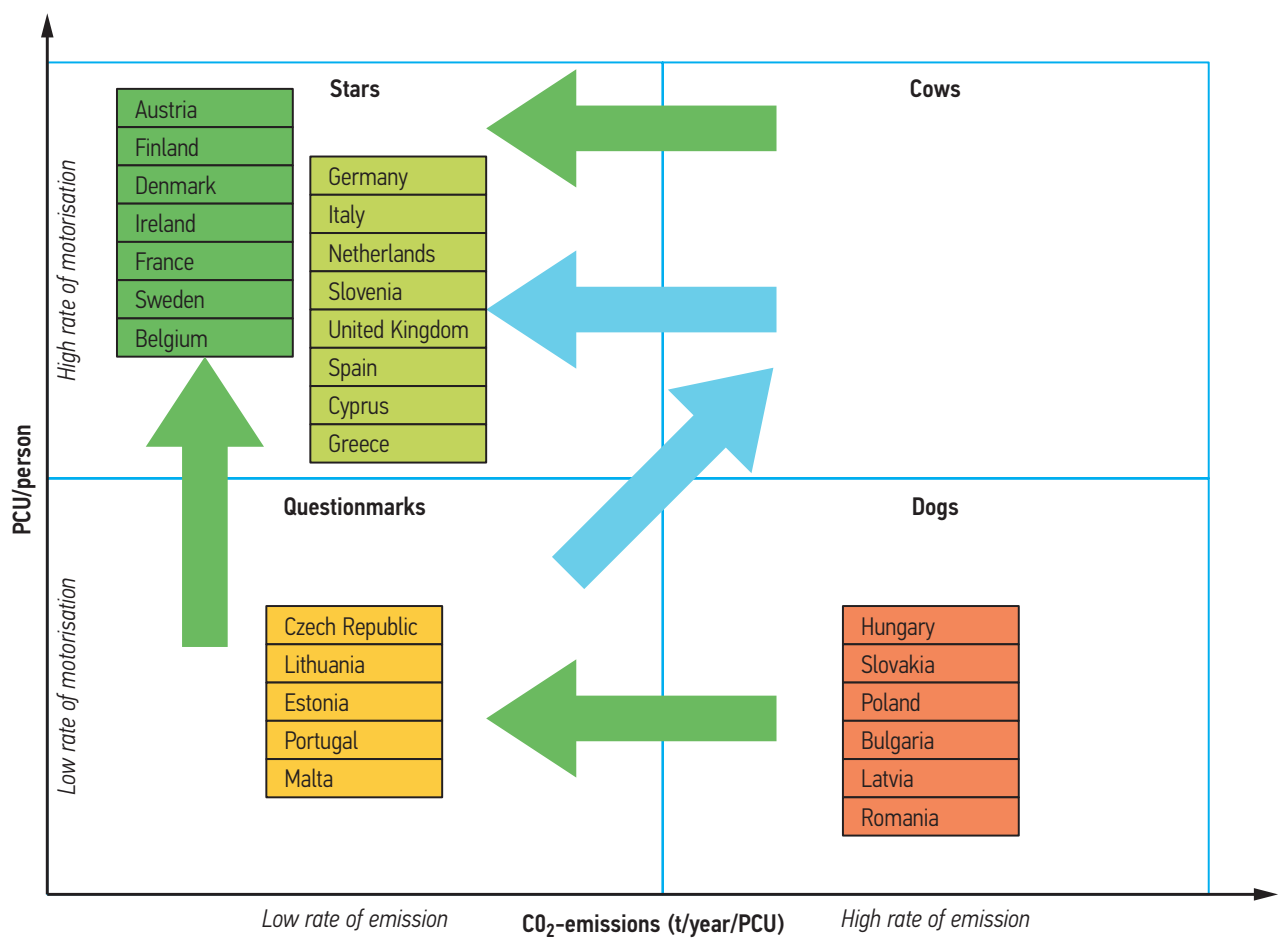

Fig. 8. Environmental BCG matrix (source: own compilation)

- Question marks (Group II) - because of the fast pace of increasing motorization, these countries could use measures to encourage the renewal of the vehicle fleet, increasing the attractiveness of alternative transport modes and fuels (Szlávik, Csete 2012). However, it has become clear that alternative fuels (especially 1st generation) also have limits with respect to their sustainability (Szendrö 2010). They have a high potential to become stars.

- Stars (Group III) - the countries in this group are mostly stagnating, having reached a kind of social equilibrium. In order to move away from this state, awareness raising, changing behaviour, environmental consciousness and other social aspects should be considered (Cooper 2007), since these countries have already reached a mature state of motorization and have implemented measures to minimize impacts from high levels of automobile dependence.

- Stars (Group IV) - these countries are economically developed, and measures that are most effective when there is a good and advanced approach to transport can be applied, e.g. car sharing, car pooling, etc. (Parker et al. 2011).

Notwithstanding the necessity for a common European vision on curbing the emissions of the transport sector, the need to acknowledge regional differences in the current status and the most efficient tools cannot be denied. The caution for social and economical differences need to be considered and require further analysis in the topic of road transport-related environmental management tools.
Identifying the most effective measures requires knowledge of the situation in each country. The present article aimed to provide one method of analysis for identifying the right tools to be adapted to maximize effectiveness of environmental protection in road transportation.

With the tools tailored to specific needs, it will become easier to meet the goals set out in the White Paper and the Climate and Energy Package, contributing to a more sustainable transport system for Europe. It is one of the important visions of the European community for the decades to come with its barriers and pitfalls that need to be investigated.

\section{Acknowledgements}

This work is connected to the scientific program of the 'Development of quality-oriented and harmonized $\mathrm{R}+\mathrm{D}+\mathrm{I}$ strategy and functional model at BME' project. These projects are supported by the New Szechenyi Development Plan (Project ID: TÁMOP-4.2.1/B-09/1/KMR2010-0002) and 'Modelling and multi-objective optimization based control of road traffic flow considering social and economical aspects' Program CNK 78168 of OTKA.

The authors are grateful to the support of Bólyai János - Research Fellowship of HAS (Hungarian Academy of Science).

Authors are grateful for the support of Prof. Dr Florian Heinitz - Director of Transport and Spatial Planning Institute in University of Applied Science in Erfurt, Germany. 


\section{References}

Beck, M. J.; Rose, J. M.; Hensher, D. A. 2011. Behavioural responses to vehicle emissions charging, Transportation 38(3): 445-463.

http://dx.doi.org/10.1007/s11116-010-9316-7

Chari, R.; Burke, T. A.; White, R. H.; Fox, M. A. 2012. Integrating susceptibility into environmental policy: an analysis of the national ambient air quality standard for lead, International Journal of Environmental Research and Public Health 9(4): 1077-1096. http://dx.doi.org/10.3390/ijerph9041077

Cooper, C. 2007. Successfully changing individual travel behavior: applying community-based social marketing to travel choice, Transportation Research Record 2021: 89-99. http://dx.doi.org/10.3141/2021-11

Csete, M.; Horváth, L. 2012. Sustainability and green development in urban policies and strategies, Applied Ecology and Environmental Research 10(2): 185-194.

EEA. 2011. Monitoring of $\mathrm{CO}_{2}$ Emissions from Vans - Regulation 510/2011. European Environment Agency (EEA) Dataset.

EEA. 2009. Monitoring of $\mathrm{CO}_{2}$ Emissions from Passenger Cars Regulation 443/2009. European Environment Agency (EEA) Dataset.

IRU. 2009. Road Transport Indices for 2009. International Road Transport Union (IRU). Available from Internet: http:// www.iru.org

ITF. 2011. Car Fleet Renewal Schemes: Environmental and Safety Impacts. International Transport Forum (ITF) 72 p. Available from Internet: http://www.internationaltransportforum.org/pub/pdf/11Fleet.pdf

Lee, R. 2011. The outlook for population growth, Science 333(6042): 569-573. http://dx.doi.org/10.1126/science.1208859

Liao, W.; Heijungs, R.; Huppes, G. 2012. Natural resource demand of global biofuels in the anthropocene: a review, Renewable and Sustainable Energy Reviews 16(1): 996-1003. http://dx.doi.org/10.1016/j.rser.2011.09.022

Parker, J.; Walker, K.; Johnson, R. 2011. What can we learn from car sharing experiences in the UK?, Proceedings of the ICE - Transport 164(3): 181-188. http://dx.doi.org/10.1680/tran.2011.164.3.181

Shroufi, A.; Chowdhury, R.; Aston, L. M.; Pashayan, N.; Franco, O. H. 2011. Measuring health: a practical challenge with a philosophical solution?, Maturitas 68(3): 210-216. http://dx.doi.org/10.1016/j.maturitas.2010.11.019

Szendrő, G. 2011. Congestion charging in Budapest - a comparison with existing systems, Periodica Polytechnica: Transportation Engineering 39(2): 99-103. http://dx.doi.org/10.3311/pp.tr.2011-2.09

Szendrő, G. 2010. Sustainable biofuels in Hungary and Europe - self-defeating incentives?, Gazdálkodás 54(24): 71-78.

Szlávik, J.; Csete, M. 2012. Climate and energy policy in Hungary, Energies 5(2): 494-517. http://dx.doi.org/10.3390/en5020494

Török, Á. 2009. Theoretical estimation of the environmental impact of biofuel mixtures, Transport 24(1): 26-29. http://dx.doi.org/10.3846/1648-4142.2009.24.26-29 